\title{
Low-cost replication of self-organized sub-micron structures into polymer films
}

\author{
H. Stenberg ${ }^{1}$, P. Stenberg ${ }^{2}$, L. Takkunen ${ }^{1}$, M. Kuittinen ${ }^{2}$, M. Suvanto ${ }^{1}$, T. T. Pakkanen ${ }^{1 *}$ \\ ${ }^{1}$ University of Eastern Finland, Department of Chemistry, P.O.Box 111, FIN-80101 Joensuu, Finland \\ ${ }^{2}$ University of Eastern Finland, Institute of Photonics, P.O.Box 111, FIN-80101 Joensuu, Finland
}

Received 9 May 2014; accepted in revised form 20 August 2014

\begin{abstract}
In this paper, the results of exploiting self-organized sub-micron polystyrene (PS) wrinkle patterns possessing random orientation, in preparation of a nickel stamp for hot embossing purposes, are presented. Self-organized patterns were prepared employing a method in which a stiff cross-linked capping layer on the topmost part of the soft polystyrene layer was created by using reactive ion etching (RIE) device with mild conditions and argon as a process gas, and the wrinkle formation was initiated thermally. Different surface patternings were obtained using silicon and stainless steel (SST) wafers as substrates. Prepared Ni-stamps were employed in hot embossing of polycarbonate (PC) and cyclo-olefin polymer (COP) films, using a nano-imprinting process. The replication quality of the self-organized wrinkle structures in PC and COP films was monitored by comparing the shape and dimensions of the original and final surface structures. The hot embossed sub-micron scale features, originally formed on stainless steel substrate, were found to have influence on the optical properties of the PC and COP films by lowering their reflectances.
\end{abstract}

Keywords: coatings, self-organization, hot-embossing, polystyrene, silicon

\section{Introduction}

Pattern formation by self-organization, employing different kinds of layered systems, for example trilayered substrate/soft layer/superstrate or bilayered hard substrate/soft layer structures, has been studied quite actively during past decades [1-5]. Both theoretical [6-9] and experimental $[10,11]$ approaches have been used to explain the phenomenon. Utilization of the self-organized patterns in various applications is of high interest [12] and it has been applied for example in the case of curved photonic crystals by Kolaric et al. [13].

It has been found out that very different kinds of materials and methods can be employed for selforganizing coatings [14-18], or the whole process set-up can be designed from end-to-start, to obtain structures with desired shapes or sizes, as a result $[19,20]$. The self-organizing pattern formation to be occurred, the structure of the layered system and materials employed must be appropriate for the process and fulfill certain requirements. For example in case of thermally induced self-organization sufficient difference in thermal expansion coefficients of individual layers is required. Also, the thickness of each material layer of the system must be optimum, for the stress driving self-organization to be developed. By tailoring the forming structures, the properties of the structured surface, like wetting or optical properties, can be influenced [21-23].

Hot embossing is a simple method to transfer desired structures into different thermoplastic polymer films [24]. The process parameters are set for each material according to the materials properties. Hot embossing enables production of different kinds of elements for e.g. optoelectronics or biomedical application purposes $[25,26]$. Furthermore, the replication, car-

\footnotetext{
${ }^{*}$ Corresponding author, e-mail: tuula.pakkanen@uef.fi

(C) BME-PT
} 
ried out by hot embossing, is easily transferred to a time saving and cost effective, high-volume roll-toroll manufacturing [27-29].

By combining the advantages of the self-organized pattern formation and the thermal imprint processing, large volumes of patterned polymer products with a specific sub-micron structuring can be prepared. For example Chou et al. [30], have previously introduced the utilization of the hot embossing with 25 nanometer resolution, but the original structures were obtained using electron beam lithography. Schweikart et al. [31], demonstrated the replication of periodic sub-micron sized wrinkles employing both micro thermoforming and molding process using epoxy resin.

In the present research, we demonstrate a controlled preparation of self-organized PS wrinkle patterns on top of silicon and stainless steel wafers and replication of these structures into polymer films by hot embossing via electro-plating the wrinkles into $\mathrm{Ni}$ stamps. This stepwise fabrication method enables development of characteristic and random submicron sized surface patterning over large surface areas without using any expensive equipments and processes. We show that the shape and size of the obtained surface structures can be influenced by varying the substrate material. Moreover, effects of this unique sub-micron sized structuring on the optical properties of the PC and COP polymer films are studied.

\section{Materials and methods}

Single-side polished silicon wafers $(\varnothing 100 \mathrm{~mm}$, $<100>$, Compart Technology Ltd.) and stainless steel (SST) wafers ( $\varnothing 100 \mathrm{~mm}$, thickness $0.5 \mathrm{~mm}$, Ruukki Metals) were cleaned 5 minutes in trichloroethylene and 5 minutes in methanol, using an ultrasonic treatment. The wafers were dried under nitrogen flow and kept in a desiccator in a nitrogen atmosphere. The native oxide layer was left intact.

The solution of PS and toluene, having the concentration of $10 \%$ (weight/volume), was prepared dissolving polystyrene with molar mass of $192000 \mathrm{~g} / \mathrm{mol}$ (Sigma-Aldrich Co.) in toluene (Merck KGaA, $99.9 \%$ ) under mixing and heating. Cleaned wafers were coated by the PS/toluene solution (PS layer thickness on Si $1.5 \mu \mathrm{m}$, and on SST $0.5 \mu \mathrm{m}$ ) employing a spin-coating technique (Laurell technologies Co., WS-400A-6NPP/LITE/10K spin-coater). Coated wafers were kept at $60^{\circ} \mathrm{C}$ for
12 hours to remove the remaining solvent and stress generated in spin-coating.

\subsection{Preparation of the self-organized PS coating}

Coated wafers were plasma treated (Oxford Instruments, Plasmalab80Plus) using reactive ion etching (RIE) equipment with mild conditions (plasma power $=30 \mathrm{~W}$, pressure $=120 \mathrm{mTorr}$, flow rate $=$ $19.8 \mathrm{sccm}$ ) and argon as a process gas, to create a cross-linked PS layer to the upper part of the PS coating. After argon plasma treatment the wafers were heated in oven at $130^{\circ} \mathrm{C}$, which is above the glass transition temperature $\left(T_{\mathrm{g}}=103^{\circ} \mathrm{C}\right)$ of the PS, for 12 hours, for wrinkles to be formed [16].

\subsection{Preparation of the hot embossing nickel stamp}

A thin Ni layer, having thickness of $35 \mathrm{~nm}$, was sputtered onto of the self-organized PS layers on top of the Si and SST wafers. The sputtered nickel was used as an initiation layer, in order to grow the $\mathrm{Ni}$ shims with a thickness of $300 \mu \mathrm{m}$ in electro-plating equipment (HEGA EFNI 01, Ni-sulfamate). Ni-shim was separated from the Si/PS or SST/PS wafers, cut to a round stamp with a diameter of $60 \mathrm{~mm}$, and cleaned using trichloroethylene and methanol.

\subsection{Hot embossing of polycarbonate (PC) and cyclo olefin polymer (COP)}

For hot embossing purposes the Ni-stamp was silanized for 10-15 minutes in a glove box in a nitrogen atmosphere using a mixture of HFE-7100 (3M) and trimethylhydroxysilane (ABCR GmbH \& Co., $0.2 \%$ in HFE-7100), after which the stamp was rinsed for 15 minutes with HFE-7100.

Hot embossing process was conducted using nanoimprinting equipment (Obducat Nanoimprinter Eitre 3) with 3" seating, and the prepared Ni-plates as stamps. Two polymer materials, PC (thickness $0.10 \mathrm{~mm}$ ) $\left(T_{\mathrm{g}}=150^{\circ} \mathrm{C}\right)[31]$ and COP (thickness $0.15 \mathrm{~mm}$ ) $\left(T_{\mathrm{g}}=140^{\circ} \mathrm{C}\right)[33]$, were patterned using parameters suitable for each material (Table 1). Hot embossing

Table 1. Hot embossing parameters

\begin{tabular}{|l|r|r|}
\hline & PC & COP \\
\hline$T_{1}\left[{ }^{\circ} \mathrm{C}\right]$ & 165 & 150 \\
\hline Pressure $[$ bar $]$ & 50 & 50 \\
\hline Time $[\mathrm{s}]$ & 120 & 180 \\
\hline$T_{2}\left[{ }^{\circ} \mathrm{C}\right]$ & 135 & 135 \\
\hline
\end{tabular}

$T_{1}$ is a hot embossing temperature, $T_{2}$ is a release temperature 

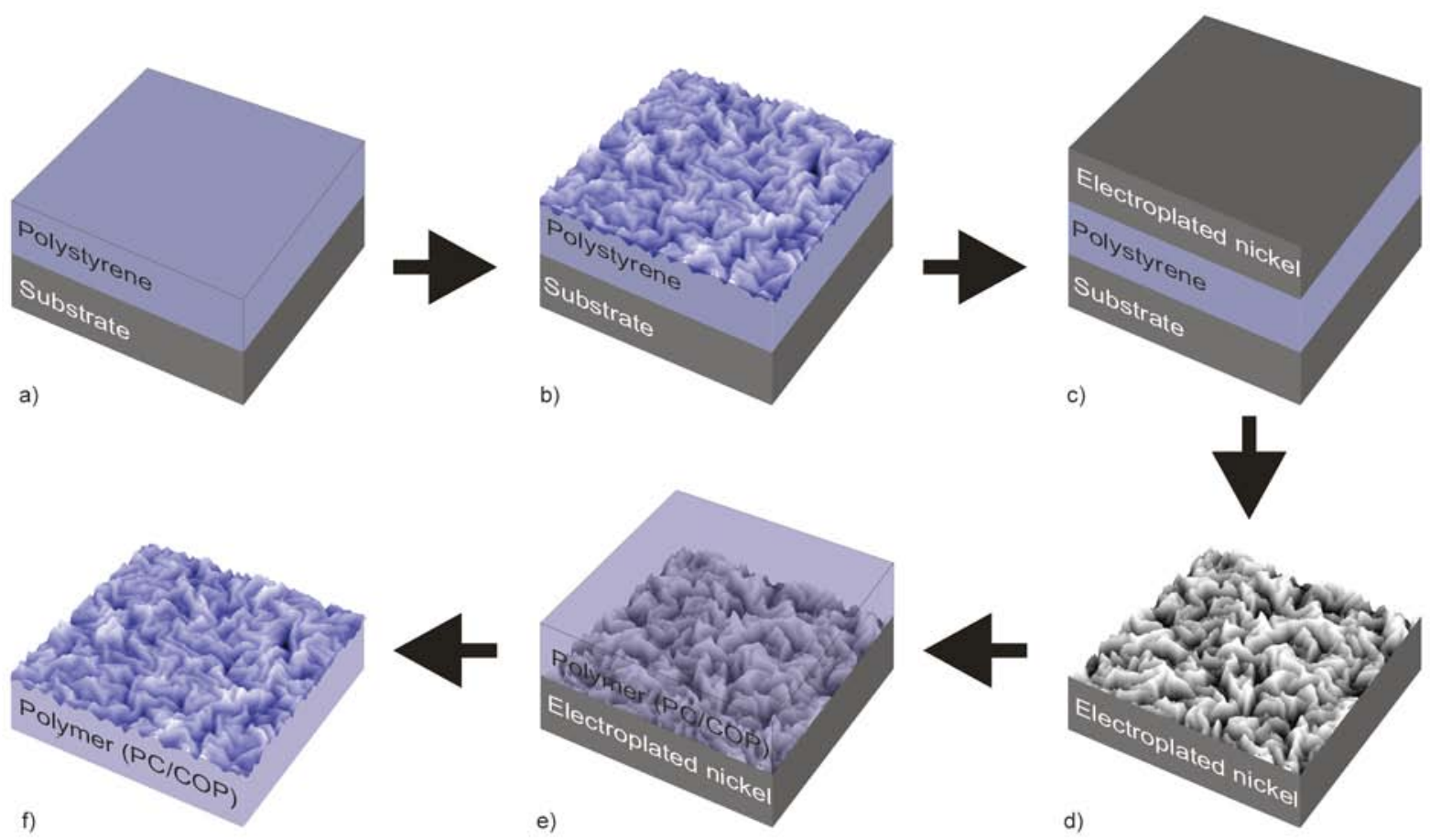

Figure 1. Schematic illustration of the hot embossing process, a) coating the substrate, b) pattern development to the PS, c) electro-plating nickel layer on top of the self-organized PS, d) nickel stamp removal, e) employing the $\mathrm{Ni}$ stamp in hot embossing, f) hot embossed PC/COP film

temperature was set above the softening temperature of the used material, whereas the release temperature was below that. The hot embossing process is represented in Figure 1.

\subsection{Characterization of the samples}

The wrinkled PS layers were observed using noncontact mode of atomic force microscope (AFM, Thermo Microscopes Explorer) with SPMlab 5.01 software. The shapes and the dimensions of the selforganized structures were analyzed using the line analysis, area analysis and peak/valley measurement tools of the software and the minimum height of an individual structure was set to $5 \mathrm{~nm}$.

For filtered power spectral density (FPSD) analysis the numerical data obtained from AFM observation of the surfaces was analyzed by Vision 4.20 pro- gram, to create the PSD curves. The PSD curves were further Fourier filtered to obtain the filtered roughness values with selected spatial frequency ranges. Static contact angles (CA) of the hot embossed and smooth un-patterned reference samples were determined (CAM 200 Optical contact angle meter) for both water and oleic acid, at the ambient temperature. For water, a drop volume of $5 \mu \mathrm{L}$ was used, whereas in case of oleic acid the volume was set to $1 \mu \mathrm{L}$. The duration of each determination was $30 \mathrm{~s}$ and the CA was measured from at least five different points. To obtain an average CA of each sample, five last values of each measurement were used in calculation.

Optical properties of the patterned and unpatterned PC and COP films were determined using UV/VIS/ NIR spectrometer (Perkin Elmer Lambda 900 UV/

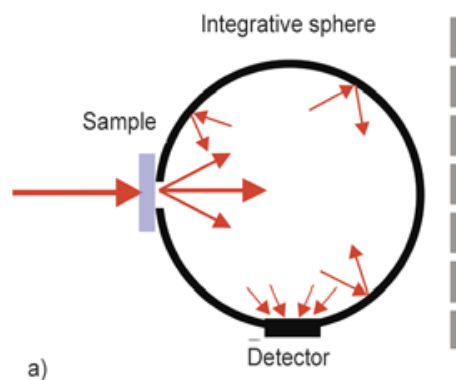

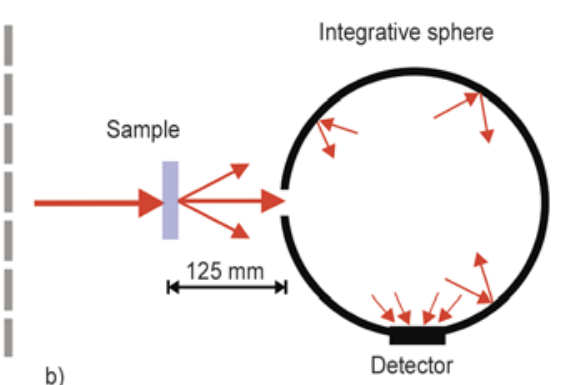

b)

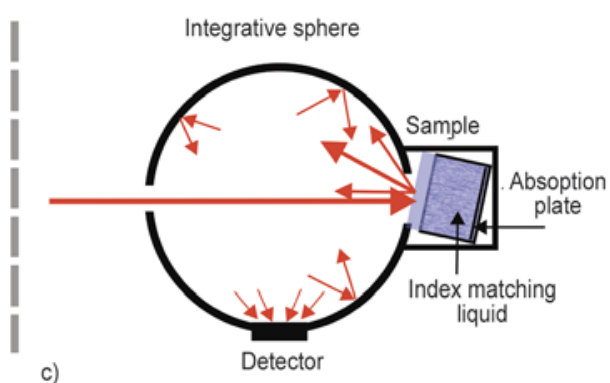

c)

Figure 2. Schematic illustration of the experimental configurations for a) transmittance, b) scattering and c) reflectance determination 
VIS/NIR) with $150 \mathrm{~mm}$ integrative sphere accessory unit. The wavelength range from 300 to $1000 \mathrm{~nm}$ was scanned with $1 \mathrm{~nm}$ step resolution. In reflectance measurements index matching liquid (Cargille Series: A, $n=1.48000$ ) and an absorption plate were used behind the sample film to prevent the backside reflection. In order to examine the scattering property of the samples, the transmittance determinations were carried out first by setting the sample in a holder at the opening of the integrative sphere and secondly by using a movable sample holder, which was placed $12.5 \mathrm{~cm}$ from the integrative sphere opening. The measurements were carried out at ambient temperature $\left(25^{\circ} \mathrm{C}\right)$, in air. The schematic illustration of the all experimental setups is presented in Figure 2.

\section{Results and discussion}

\subsection{Fabrication of the structured surfaces}

In order to develop a patterned PS layer on top of the polystyrene coated Si and SST wafers, a stiff superstrate was created by cross-linking the uppermost layer of the PS coating by employing a plasma treatment with a mild conditions [16] and argon as a
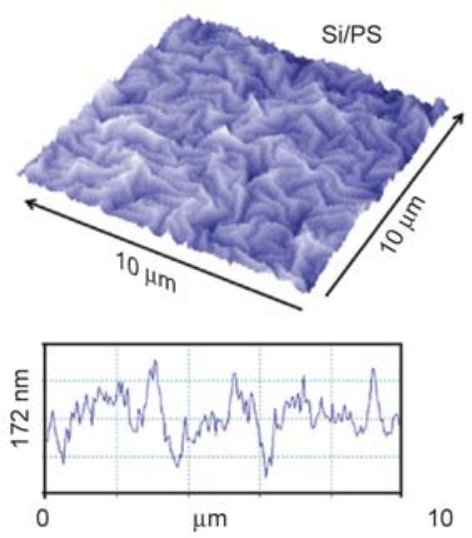

a)

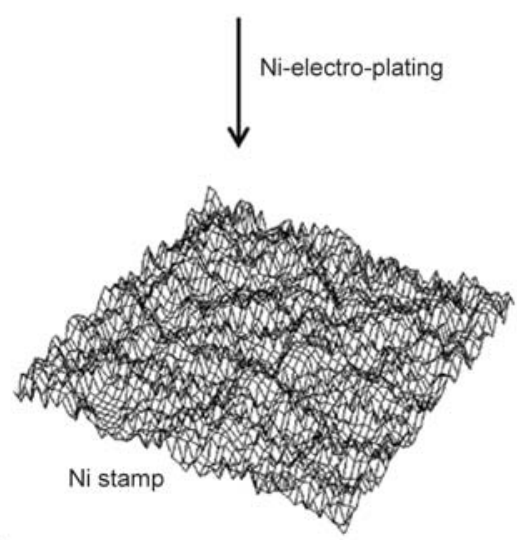

c)

Figure 3. AFM images $(10 \mu \mathrm{m} \times 10 \mu \mathrm{m})$ and topography graphs $(10 \mu \mathrm{m})$ of self-organized PS patterns formed on (a) Si and (b) SST wafer and transferred to Ni-stamp as negation (c) and (d) process gas, after which the pattern formation was obtained by annealing. Use of the SST wafer enabled a study of the influence of the substrate with a characteristic surface structure, on the self-organized pattern formation and the shape and dimensions of the patterns of polystyrene.

Patterns of the PS layer obtained employing Si substrate, possessed a shape of wrinkles (Figure 3a). The highest wrinkles were about $200 \mathrm{~nm}$, whereas the average height value, determined for the whole scanned area $(10 \times 10 \mu \mathrm{m})$, was about $100 \mathrm{~nm}$ (Figure 3a). The average period (peak-to-peak) was determined to be about $240 \mathrm{~nm}$. The surface of the Nistamp, prepared on top of the wrinkled PS layer is a negative of the original surface pattern (Figure 3c). The surface of an uncoated SST wafer composed of characteristic island-like structures having height from 300 to $500 \mathrm{~nm}$, determined by AFM [15]. The self-organized patterns of PS film formed on the SST substrate also possessed a shape of wrinkles (Figure 3b). The average wrinkle height was $210 \mathrm{~nm}$ and the highest wrinkles were $390 \mathrm{~nm}$. The average period (peak-to-peak) was determined to $400 \mathrm{~nm}$.

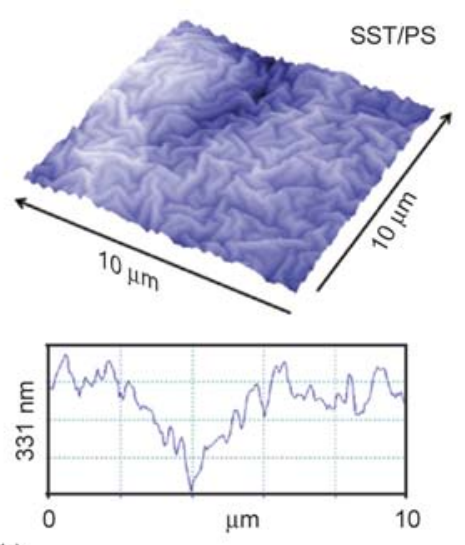

b)

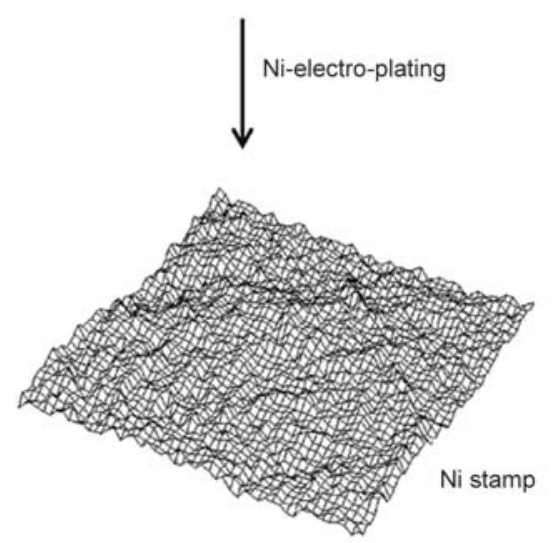

d) 


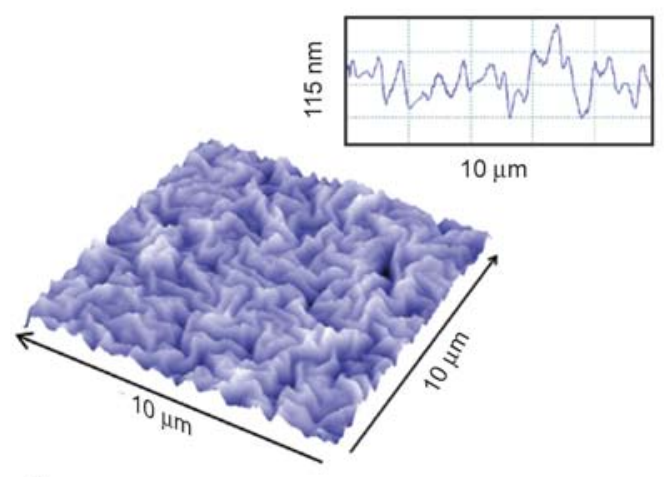

a)

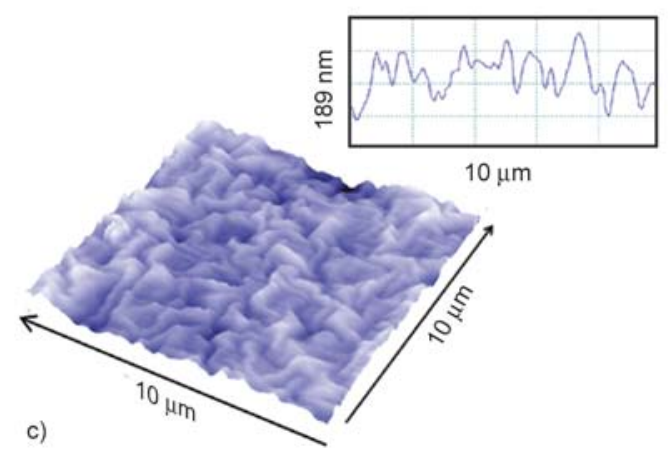

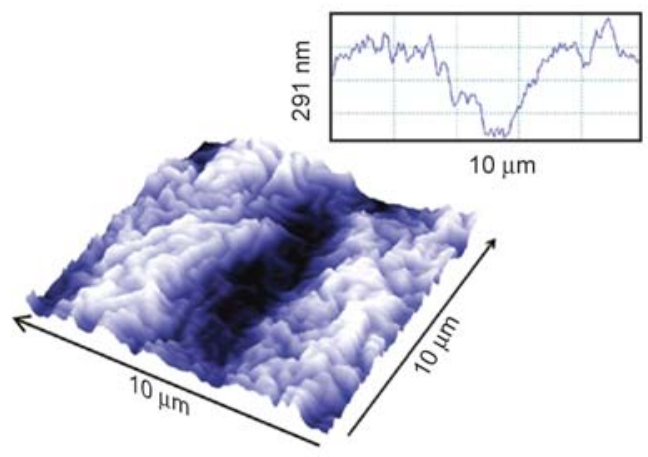

b)

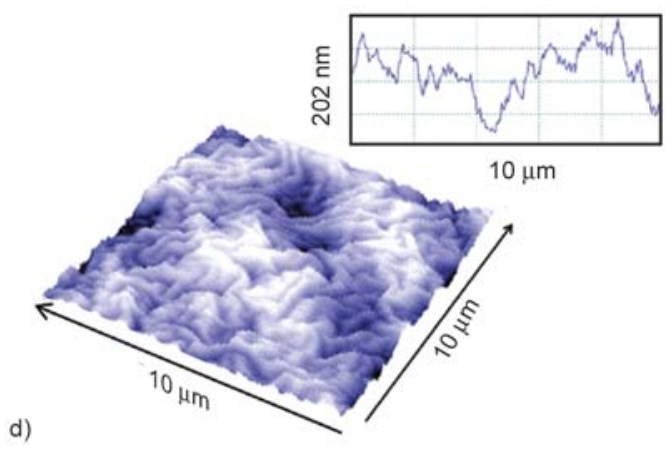

Figure 4. AFM images $(10 \mu \mathrm{m} \times 10 \mu \mathrm{m})$ and topography graphs $(10 \mu \mathrm{m})$ of the hot embossed PC and COP films; (a) PC/Si, (c) $\mathrm{COP} / \mathrm{Si}$, (b) PC/SST, (d) COP/SST

Dimensions of the surface patterns were determined employing area analysis tool of the AFM software from the whole scanned area $(10 \times 10 \mu \mathrm{m})$. Figure $3 \mathrm{~d}$ shows the wrinkles, transferred from the $\mathrm{SST} / \mathrm{PS}$ wafer to the Ni plate.

Self-organized structures formed on PS coated Si and SST wafers, were successfully replicated onto PC and COP films with thicknesses of 0.10 and $0.15 \mathrm{~mm}$, respectively (Figure 4). Dimensions of the wrinkles on the hot embossed polymers were determined by AFM. The average height value of the replicated wrinkles employing the Si substrate was about $100 \mathrm{~nm}$ (Table 2) and the largest heights $200 \mathrm{~nm}$. Copied structures on the patterned polymers (PC, COP) show some characteristic shapes of the SST wafer (Figure $4 \mathrm{~b}$ and $4 \mathrm{~d}$ ) island-like features.

Table 2. Average dimensions of the self-organized patterns on original and hot embossed surfaces

\begin{tabular}{|l|c|c|}
\hline \multicolumn{1}{|c|}{ Sample } & $\begin{array}{c}\text { Average height } \\
{[\mathbf{n m}]}\end{array}$ & $\begin{array}{c}\text { Average period } \\
{[\boldsymbol{\mu} \mathbf{m}]}\end{array}$ \\
\hline $\mathrm{Si} / \mathrm{PS}$ & 100 & 0.24 \\
\hline $\mathrm{PC}_{\text {hot embossed, } \mathrm{Si}}$ & 90 & 0.77 \\
\hline $\mathrm{COP}$ hot embossed, $\mathrm{Si}$ & 90 & 0.65 \\
\hline $\mathrm{SST} / \mathrm{PS}$ & 210 & 0.40 \\
\hline $\mathrm{PC}_{\text {hot embossed, } \mathrm{SST}}$ & 130 & 0.28 \\
\hline $\mathrm{COP}_{\text {hot embossed, } \mathrm{SST}}$ & 120 & 0.23 \\
\hline
\end{tabular}

\subsection{Replication quality}

The replication fidelity of the self-organized wrinkles on the PC and COP films was evaluated employing power spectral density analysis with filtered roughness values (FPSD) [34, 35]. This analysis gives detailed information mainly of the structure periodicities and is based on the numerical data obtained from the AFM determinations of the original wrinkled surfaces and the replicated PC and COP films.

In the case of self-organized structures formed on Si substrate (Figure 5a, Si/PS), the spectral density curve and the filtering results of the corresponding roughness show a large amount of the surface roughness to be centered in the filtering ranges 100 $500 \mathrm{~nm}$ and $1-10 \mu \mathrm{m}$, whereas area $500-1000 \mathrm{~nm}$ contains less spectral density. The AFM observation of the wrinkled Si/PS surface patterns (Figure 3a) showed the structure consisting of both smaller and larger wrinkles with an average period value of $240 \mathrm{~nm}$. Therefore, the results obtained by FPSD are in line with the findings of AFM analysis.

Comparison between the filtered roughness values of hot embossed polymer films (PC and COP) and the original surface $(\mathrm{Si} / \mathrm{PS})$ shows a quite similar trend for all samples; the filtering ranges $100-500 \mathrm{~nm}$ 

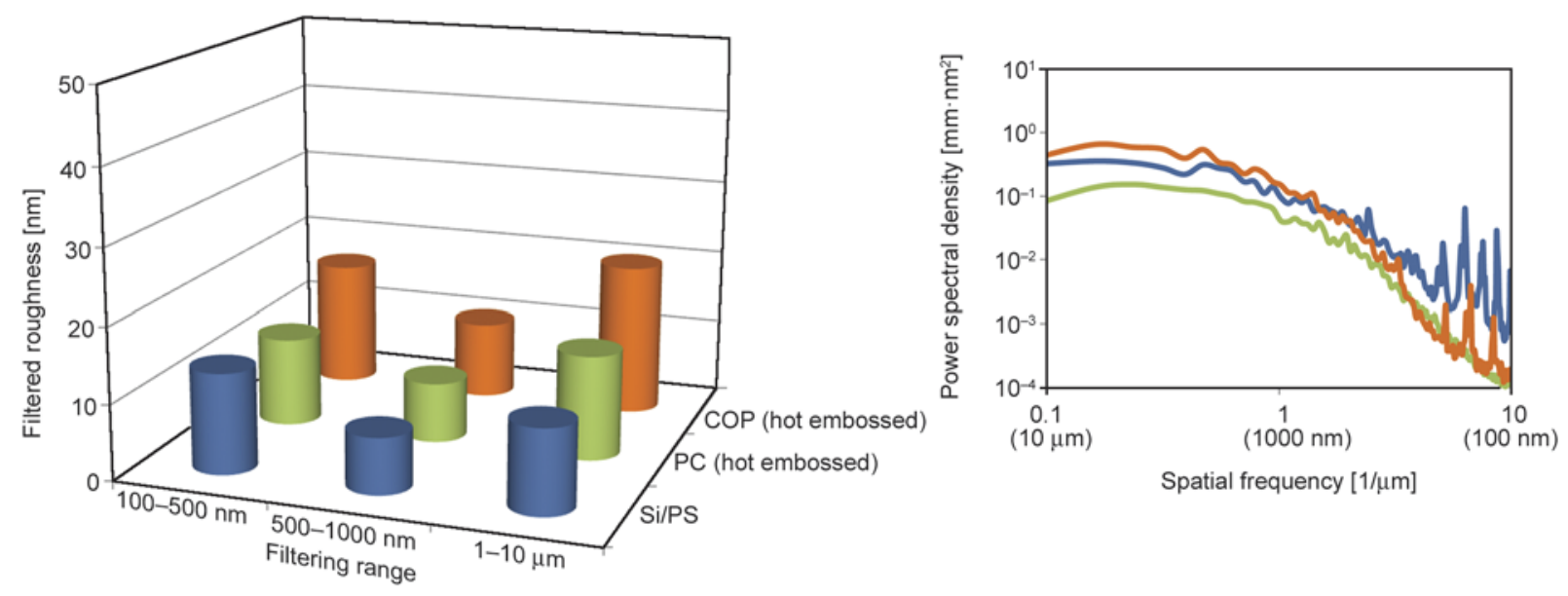

a)
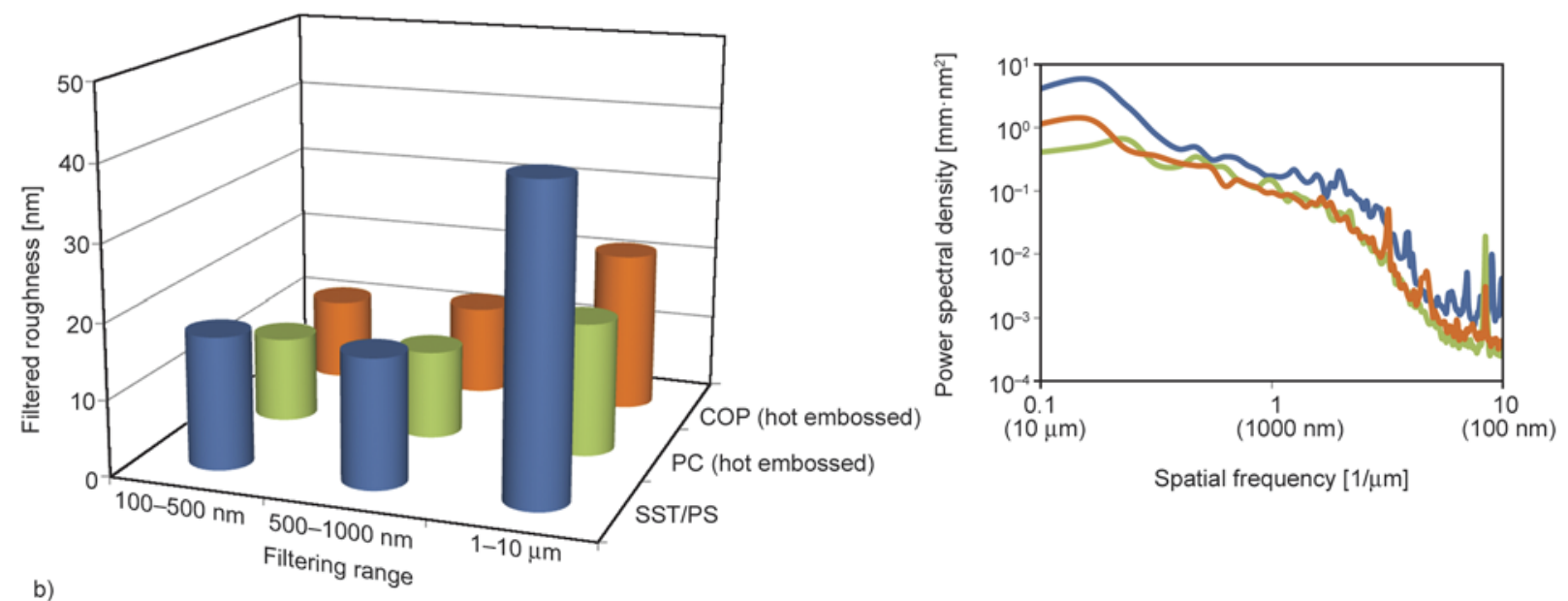

Figure 5. PSD analysis results of wrinkled surfaces formed on (a) Si substrate and (b) SST substrate, and replicated to PC and COP films by hot embossing

and $1-10 \mu \mathrm{m}$ contain more roughness than the range 500-1000 nm (Figure 5a). The original wrinkled surface contains a lot of small peaks, which seem to have vanished due to replication process. This influences the values of average wrinkle periods. Even though, lacking the smallest wrinkles, the patterning of $\mathrm{PC}_{\text {hot embossed, } \mathrm{Si}}$ and $\mathrm{COP}_{\text {hot embossed, } \mathrm{Si} \text {, still }}$ include quite a large amount of roughness with the periodicity located in the filtering range 100 $500 \mathrm{~nm}$.

According to the FPSD analysis of the original SST substrate with the self-organized PS coating on top of it, the highest proportion of surface roughness is concentrated in the filtering range $1-10 \mu \mathrm{m}$, but also located in the filtering ranges $100-500 \mathrm{~nm}$ and 500 $1000 \mathrm{~nm}$ are present (Figure 5b, SST/PS). By AFM observation the average period of these structures was determined to about $400 \mathrm{~nm}$. A large proportion of the roughness in the range $1-10 \mu \mathrm{m}$ in the FPSD analysis is probably due to characteristic island-like surface structure of the uncoated SST wafer. The roughness distributions of the hot embossed PC and COP films (Figure 5b) resemble the FPSD result of the original SST/PS. AFM analysis of the $\mathrm{PC}_{\text {hot embossed, SST }}$ and $\mathrm{COP}_{\text {hot embossed, SST }}$ gave the average period values of 0.28 and $0.23 \mu \mathrm{m}$ (Table 2), respectively.

\subsection{Surface and optical properties}

Static contact angles (CA) of water and oleic acid were determined for both the unpatterned reference and hot embossed polymer samples. In case of PC the water CAs of patterned and unpatterned samples were almost the same, the values being $83-87^{\circ}$. In case of oleic acid the contact angles of the PC samples increased from 6 to $14^{\circ}\left(\mathrm{PC}_{\text {hot embossed, } \mathrm{Si}}\right)$ and to $12^{\circ}\left(\mathrm{PC}_{\text {hot embossed, SST }}\right)$ due to the surface patterning. The CA values of COP samples showed the patterning having no significant influence on water or oleic acid CAs of the material; the CA of water was 

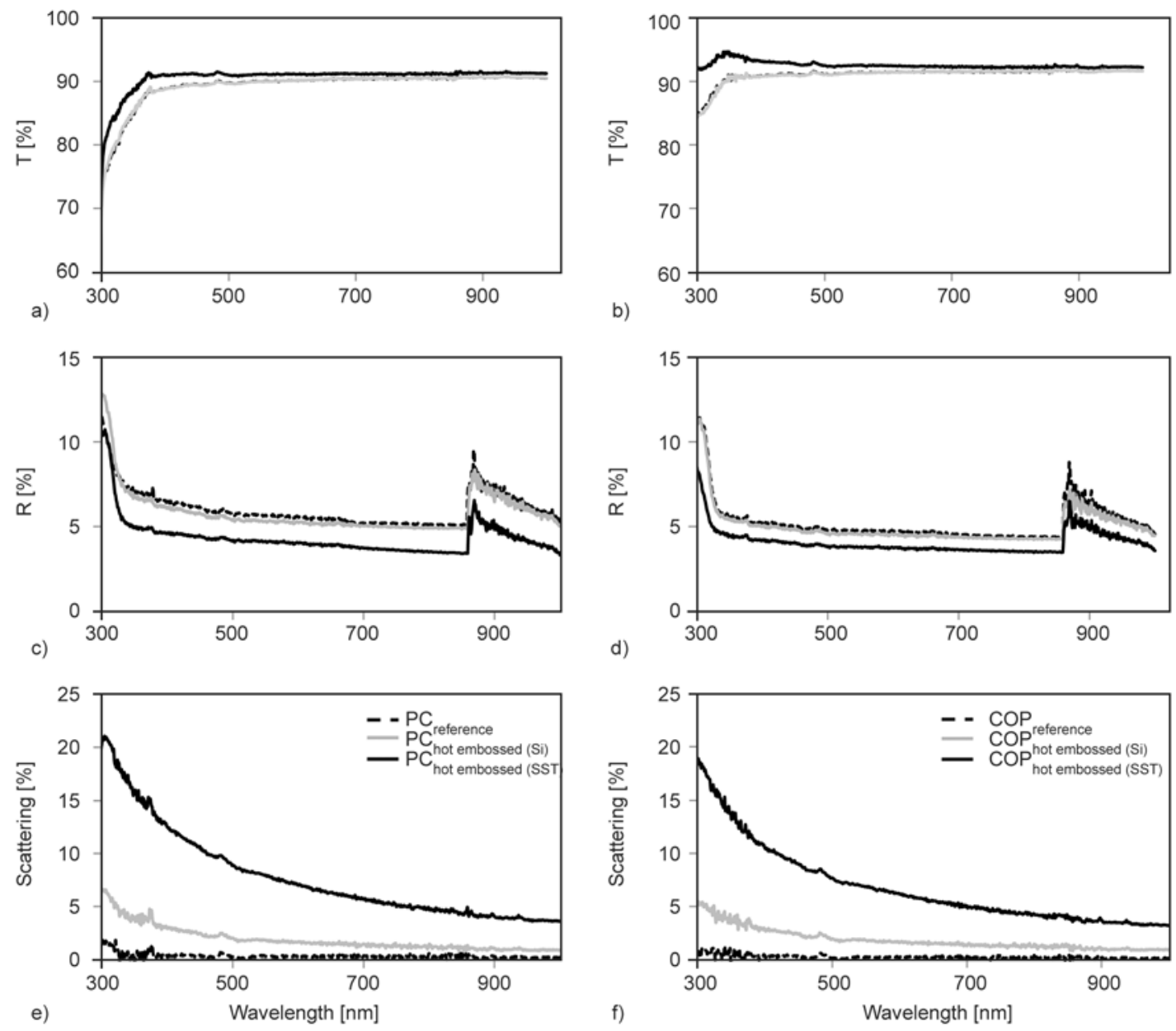

Figure 6. Transmittances, reflectances and scatterings of the reference and hot embossed PC (a, c, e) and COP (b, d, f) films

lowered $2-3^{\circ}$ from the value of the smooth reference $\left(101^{\circ}\right)$ and the CA of oleic acid remained the same being $4-5^{\circ}$.

Influence of the hot embossed patterning on the transparency, reflectivity and scattering properties of the PC and COP films, was observed by determining transmittance and reflectance values of the reference and patterned samples using the UV/VIS/ NIR spectrometer in the wavelength range of 300 $1000 \mathrm{~nm}$. In the case of reflectance determinations, scattering was ignored. Values of the determined properties at the wavelengths 450,530 and $610 \mathrm{~nm}$, corresponding the prime colors of blue, green and red [36], respectively, are collected in Table 3.

Comparison between the transmittance values of the smooth PC and COP reference samples and corresponding hot embossed samples reveals that the wrinkle structures originally formed on SST substrate slightly increase the transmittance of the polymer films (Figure 6), whereas the wrinkles developed on silicon wafer have no effect on this property. Reflectances of the patterned and the reference samples were determined employing index matching liquid and absorption plate behind the sample to

Table 3. UV/VIS results of the unpatterned reference and hot embossed PC and COP samples at the wavelengths 450,530 and $610 \mathrm{~nm}$

\begin{tabular}{|c|c|c|c|c|c|c|c|c|c|}
\hline \multirow[t]{2}{*}{ Sample } & \multicolumn{3}{|c|}{$\begin{array}{c}\text { Transmittance } \\
{[\%]}\end{array}$} & \multicolumn{3}{|c|}{$\begin{array}{c}\text { Reflectance } \\
{[\%]}\end{array}$} & \multicolumn{3}{|c|}{$\begin{array}{c}\text { Scattering } \\
{[\%]}\end{array}$} \\
\hline & $450 \mathrm{~nm}$ & $530 \mathrm{~nm}$ & $610 \mathrm{~nm}$ & $450 \mathrm{~nm}$ & $530 \mathrm{~nm}$ & $610 \mathrm{~nm}$ & $450 \mathrm{~nm}$ & $530 \mathrm{~nm}$ & $610 \mathrm{~nm}$ \\
\hline $\mathrm{PC}_{\text {reference }}$ & 89.5 & 89.9 & 90.1 & 6.1 & 5.7 & 5.6 & 0.3 & 0.3 & 0.3 \\
\hline $\mathrm{PC}_{\text {hot embossed, } \mathrm{Si}}$ & 89.4 & 89.9 & 90.1 & 5.8 & 5.4 & 5.3 & 2.7 & 1.9 & 1.6 \\
\hline $\mathrm{PC}_{\text {hot embossed, } \mathrm{SST}}$ & 91.1 & 91.0 & 91.1 & 4.4 & 4.2 & 4.0 & 11.2 & 8.3 & 6.9 \\
\hline $\mathrm{COP}_{\text {reference }}$ & 91.1 & 91.3 & 91.5 & 5.0 & 4.8 & 4.8 & 0.3 & 0.2 & 0.2 \\
\hline $\mathrm{COP}_{\text {hot embossed, } \mathrm{Si}}$ & 91.0 & 91.2 & 91.4 & 4.8 & 4.6 & 4.5 & 2.4 & 1.9 & 1.6 \\
\hline $\mathrm{COP}_{\text {hot embossed, SST }}$ & 92.8 & 92.5 & 92.4 & 4.0 & 3.8 & 3.8 & 8.9 & 7.2 & 6.0 \\
\hline
\end{tabular}


prevent the backside reflection. For PC and COP materials the reflectance values of the unpatterned reference and the corresponding hot embossed samples patterned with the structures formed on Si substrate, were almost the same (Table 3 ). In case of $\mathrm{PC}_{\text {hot embossed (SST) }}$ patterned with structures formed on SST substrate, the reflectance value $(610 \mathrm{~nm})$ was $28 \%$ lower compared with the smooth PC reference sample, being $4.0 \%$. By structuring the COP film with patterns formed on SST wafer $\left(\mathrm{COP}_{\text {hot embossed (SST) }}\right)$ the reflectivity of the material was lowered $20 \%$ and the reflectance value of $3.8 \%$ $(610 \mathrm{~nm})$ was obtained (Table 3$)$. The irregularity at the wavelength of $860 \mathrm{~nm}$ (Figure $6 \mathrm{c}$ and $6 \mathrm{~d}$ ) is due to the detector change.

Analyzing the PC samples revealed the scattering property been increased due to structuring the polymer film by hot embossing (Figure 6). For $\mathrm{PC}_{\text {reference }}$ the scattering was $0.3 \%(610 \mathrm{~nm})$ and the value of $\mathrm{PC}_{\text {hot embossed (Si) }} 1.6 \%(610 \mathrm{~nm})$. Applying the patterns formed on SST substrate onto the PC films ( $\left.\mathrm{PC}_{\text {hot embossed (SST) }}\right)$ resulted in material possessing $6.9 \%$ scattering (Table 3 ). For COP films the corresponding values were $\mathrm{COP}_{\text {reference }} 0.2 \%$, $\mathrm{COP}_{\text {hot embossed (Si) }} 1.6 \%$ and $\mathrm{COP}_{\text {hot embossed (SST) }}$ $6.0 \%$ (Table 3 ). The influence of the structures, formed on Si and SST wafers and replicated by hot embossing into PC and COP films, on the scattering property of these materials is notable.

For patterned PC/COP films with a wrinkled surface structure, certain material and structural requirements must be fulfilled in order to obtain structured polymer films possessing anti-reflective (AR) properties. In the case of transparent PC and COP materials with refractive indices close to $1.5[37,38]$, Fresnel reflection occurs at the air/polymer interface [39], due to the large difference in index values of air and polymer [40]. By patterning the surface of the polymer film with sub-wavelength relief structures with an optimized period, depth and filling factor, the refractive index of air is gradually increased to the value of the employed polymer material, leading to the reduced reflection from the film surface $[25,41]$. Therefore, in the case of the hot embossed and wrinkle structured PC and COP films, significantly lowered reflectance values over the observed wavelength area can be achieved, when the shape and dimensions of the replicated patterns meet the requirements for AR coating. In contrast to the patterned sur- faces with precise structuring and tailored AR properties, the spontaneous self-organization yields patterns with random orientation and topology, and resembling the stochastic surface structure presented by Gombert et al. [42]. In order to obtain enhanced optical properties, like anti-reflectivity, the composition of the system undergoing selforganization, as well as the initiation method, could be tailored to produce the desired surface reliefs.

\section{Conclusions}

Self-organized structure formation on polymer thin films is a phenomenon, which is quite vastly studied, but rather seldom utilized in applications. In this research the replication of a characteristic and unique surface structure firstly into a nickel stamp and further into selected polymer films, is demonstrated. The results show that the obtained wrinkle structures have a slight influence on the wetting of the $\mathrm{PC}$ and COP films. The transmittance and reflectance determinations of the PC and COP samples reveal the scattering been somewhat increased and the reflectivity of the materials been lowered, due to hot embossed patterning. Optimization of the shapes and dimensions of the self-organized structures gives a tool for a further improvement of, e.g., wettability and optical properties of different materials. The self-organized pattern formation enables fabrication of patterns with a variety of configurations and possessing a size-scale from nano- to micrometer. The present method, carried out using hot embossing process, is cost-effective and easily transferred also into a mass production.

\section{Acknowledgements}

Great acknowledgements to $\mathrm{PhD}$ Hemmo Tuovinen for help with the UV/VIS determinations. Laboratory engineer Tommi Itkonen is thanked for preparing the Ni-plates. Financial support from the European Union/European Regional Development Fund (ERDF, PRI project) is gratefully acknowledged.

\section{References}

[1] Li B., Cao Y-P., Feng X-Q., Gao H.: Mechanics of morphological instabilities and surface wrinkling in soft materials: A reviw. Soft Matter, 8, 5728-5745 (2012). DOI: $10.1039 / \mathrm{C} 2 \mathrm{SM} 00011 \mathrm{C}$

[2] Niu K., Talreja R.: Modeling of wrinkling in sandwich panels under compression. Journal of Engineering Mechanics, 125, 875-883 (1999).

DOI: 10.1061/(ASCE)0733-9399(1999)125:8(875) 
[3] Chung J. Y., Nolte A. J., Stafford C. M.: Surface wrinkling: A versatile platform for measuring thin-film properties. Advanced Materials, 23, 349-368 (2011).

DOI: 10.1002/adma.201001759

[4] Chan E. P., Page K. A., Im S. H., Patton D. L., Huang R., Stafford C. M.: Viscoelastic properties of confined polymer films measured via thermal wrinkling. Soft Matter, 5, 4638-4641 (2009).

DOI: $10.1039 / \mathrm{B} 916207 \mathrm{~K}$

[5] Genzer J., Groenewold J.: Soft matter with hard skin: From skin wrinkles to templating and material characterization. Soft Matter, 2, 310-323 (2006).

DOI: 10.1039/B516741H

[6] Léotoing L., Drapier S., Vautrin A.: First applications of a novel unified model for global and local buckling of sandwich columns. European Journal of Mechanics - A/Solids, 21, 683-701 (2002).

DOI: 10.1016/S0997-7538(02)01229-9

[7] Koissin V., Shipsha A., Skvortsov C.: Wrinkling in sandwich panels - An analytical approach. Journal of Sandwich Structures and Materials, 13, 705-730 (2011). DOI: $10.1177 / 1099636211419129$

[8] Steigmann D. J.: Tension-field theory. Proceedings of the Royal Society A, 429, 141-173 (1990).

DOI: $10.1098 /$ rspa.1990.0055

[9] Cao Y., Hutchinson J. W.: From wrinkles to creases in elastomers: The instability and imperfection-sensitivity of wrinkling. Proceedings of the Royal Society A, 468, 94-115 (2012).

DOI: $10.1098 /$ rspa.2011.0384

[10] Sun J-Y., Xia S., Moon M-W., Oh K-H., Kim K-S.: Folding wrinkles of a thin stiff layer on a soft substrate. Proceedings of the Royal Society A, 468, 932953 (2012).

DOI: $10.1098 /$ rspa.2011.0567

[11] Lei H., Payne J. A., McCormick A. V., Francis L. F., Gerberich W. W., Scriven L. E.: Stress development in drying coatings. Journal of Applied Polymer Science, 81, 1000-1013 (2001).

DOI: 10.1002/app.1522

[12] Chen C-M., Yang S.: Wrinkling instabilities in polymer films and their applications. Polymer International, 61, 1041-1047 (2012).

DOI: $10.1002 /$ pi.4223

[13] Kolaric B., Desprez S., Brau F., Damman P.: Design of curved photonic crystal using swelling induced instabilities. Journal of Materials Chemistry, 22, 1620516208 (2012).

DOI: $10.1039 / \mathrm{c} 2 \mathrm{jm} 32997 \mathrm{~b}$

[14] Chen Y-C., Crosby A. J.: Wrinkling of inhomogeneously strained thin polymer films. Soft Matter, 9, 4347 (2013).

DOI: $10.1039 / \mathrm{C} 2 \mathrm{SM} 26822 \mathrm{~A}$

[15] Stenberg H., Stenberg P., Suvanto M., Pakkanen T. T.: Self-organized pattern formation on silicon, stainless steel and zinc coated steel substrates. Progress in Organic Coatings, 77, 131-135 (2014).

DOI: $10.1016 /$ j.porgcoat.2013.08.013
[16] Stenberg H., Maaranen J., Suvanto M., Pakkanen T. T.: Solvent-assisted and thermal wrinklings of argon plasma treated polystyrene coatings on silicon substrate. Surface and Coatings Technology, 238, 133-138 (2014). DOI: $10.1016 /$ j.surfcoat.2013.10.060

[17] Katzenstein J. M., Janes D. W., Cushen J. D., Hira N. B., McGuffin D. L., Prisco N. A., Ellison C. J.: Patterning by photochemically directing the marangoni effect. ACS Macro Letters, 1, 1150-1154 (2012).

DOI: $10.1021 / \mathrm{mz} 300400 \mathrm{p}$

[18] Bonaccurso E., Graf K.: Nanostructuring effect of plasma and solvent treatment on polystyrene. Langmuir, 20, 11183-11190 (2004).

DOI: $10.1021 / 1 \mathrm{a} 0364410$

[19] Schweikart A., Fery A.: Controlled wrinkling as a novel method for the fabrication of patterned surfaces. Microchimica Acta, 165, 249-263 (2009). DOI: $10.1007 / \mathrm{s} 00604-009-0153-3$

[20] Torres J. M., Stafford C. M., Uhrig D., Vogt B. D.: Impact of chain architecture (branching) on the thermal and mechanical behavior of polystyrene thin films. Journal of Polymer Science Part B: Polymer Physics, 50, 370-377 (2012). DOI: $10.1002 /$ polb.23014

[21] Chung J. Y., Youngblood J. P., Stafford C. M.: Anisotropic wetting on tunable micro-wrinkled surfaces. Soft Matter, 3, 1163-1169 (2007). DOI: 10.1039/B705112C

[22] Lin P-C., Yang S.: Mechanically switchable wetting on wrinkled elastomers with dual-scale roughness. Soft Matter, 5, 1011-1018 (2009).

DOI: $10.1039 / \mathrm{B} 814145 \mathrm{~B}$

[23] Celia E., Darmanin T., de Givenchy E. T., Amigoni S., Guittard F.: Recent advances in designing superhydrophobic surfaces. Journal of Colloid and Interface Science, 402, 1-18 (2013).

DOI: $10.1016 /$ j.jcis.2013.03.041

[24] Becker H., Heim U.: Hot embossing as a method for the fabrication of polymer high aspect ratio structures. Sensors and Actuators A: Physical, 83, 130-135 (2000). DOI: $10.1016 / \mathrm{S} 0924-4247(00) 00296-\mathrm{X}$

[25] David C., Häberling P., Schnieper M., Söchtig J., Zschokke C.: Nano-structured anti-reflective surfaces replicated by hot embossing. Microelectronic Engineering, 61-62, 435-440 (2002).

DOI: $10.1016 / \mathrm{S} 0167-9317(02) 00425-2$

[26] Lee G-B., Chen S-H., Huang G-R., Sung W-C., Lin YH.: Microfabricated plastic chips by hot embossing methods and their applications for DNA separation and detection. Sensors and Actuators B: Chemical, 75, 142-148 (2001). DOI: $10.1016 / \mathrm{S} 0925-4005(00) 00745-0$

[27] Gale M. T.: Replication techniques for diffractive optical elements. Microelectronic Engineering, 34, 321-339 (1997).

DOI: $10.1016 / \mathrm{S} 0167-9317(97) 00189-5$ 
[28] Stuart C., Chen Y.: Roll in and roll out: A path to highthroughput nanoimprint lithography. ACS Nano, 3, 2062-2064 (2009).

DOI: $10.1021 / \mathrm{nn} 9008356$

[29] Gale M. T., Gimkiewicz C., Obi S., Schnieper M., Söchtig J., Thiele H., Westenhöfer S.: Replication technology for optical microsystems. Optics and Lasers in Engineering, 43, 373-386 (2005).

DOI: 10.1016/j.optlaseng.2004.02.007

[30] Chou S. Y., Krauss P. R., Renstrom P. J.: Imprint lithography with 25-nanometer resolution. Science, 272, 8587 (1996).

DOI: $10.1126 /$ science. 272.5258 .85

[31] Schweikart A., Zimin D., Handge U. A., Bennemann M. Altstädt V., Fery A., Koch K.: Fabrication of artificial petal sculptures by replication of sub-micron surface wrinkles. Macromolecular Chemistry and Physics, 211, 259-264 (2010).

DOI: $10.1002 /$ macp. 200900543

[32] Callister W. D., Rethcwisch D. G.: Materials science and engineering. Wiley, Hoboken (2011).

[33] Kohara T.: Development of new cyclic olefin polymers for optical uses. Macromolecular Symposia, 101, 571-579 (1996).

DOI: 10.1002/masy.19961010163

[34] Vepsäläinen L., Pääkkönen P., Suvanto M., Pakkanen T. A.: Frequency analysis of micropillar structured surfaces: A characterization and design tool for surface texturing. Applied Surface Science, 263, 523-531 (2012). DOI: $10.1016 /$ j.apsusc. 2012.09.098

[35] Vepsäläinen L., Stenberg P., Pääkkönen P., Kuittinen M., Suvanto M., Pakkanen T. A.: Roughness analysis for textured surfaces over several orders of magnitudes. Applied Surface Science, 284, 222-228 (2013).

DOI: $10.1016 /$ j.apsusc.2013.07.085
[36] Brill M. H.: A theorem on prime-color wavelengths. Color Research and Applications, 21, 239-240 (1996). DOI: 10.1002/(SICI)1520-6378(199606)21:3<239::

$$
\text { AID-COL6>3.0.CO;2-T }
$$

[37] Kasarova S. N., Sultanova N. G., Ivanov C. D., Nikolov I. D.: Analysis of the dispersion of optical plastic materials. Optical Materials, 29, 1481-1490 (2007). DOI: $10.1016 /$ j.optmat.2006.07.010

[38] Khanarian G., Celanese H.: Optical properties of cyclic olefin copolymers. Optical Engineering, 40, 10241029 (2001). DOI: $10.1117 / 1.1369411$

[39] Kikuta H., Toyota H., Yu W.: Optical elements with subwavelength structured surfaces. Optical Review, 10, 63-73 (2003). DOI: $10.1007 / \mathrm{s} 10043-003-0063-2$

[40] Chattopadhyay S., Huang Y. F., Jen Y. J., Ganguly A., Chen K. H., Chen L. C.: Anti-reflecting and photonic nanostructurfes. Materials Science and Engineering R: Reports, 69, 1-35 (2010). DOI: $10.1016 /$ j.mser.2010.04.001

[41] Päivänranta B., Saastamoinen T., Kuittinen M.: A wide-angle antireflection surface for the visible spectrum. Nanotechnology, 20, 375301/1-375301/7 (2009). DOI: 10.1088/0957-4484/20/37/375301

[42] Gombert A., Glaubitt W., Rose K., Dreibholz J., Bläsi B., Heinzel A., Sporn D., Döll W., Wittwer V.: Subwavelength-structured antireflective surfaces on glass. Thin Solid Films, 351, 73-78 (1999). DOI: 10.1016/S0040-6090(98)01780-5 